\title{
Birmingham Medical Research Expeditionary Society 1977 Expedition: The diuresis and related changes during a trek to high altitude
}

\author{
A. HOWELL* \\ M.Sc., B.Sc., M.B. B.S., M.R.C.P. \\ D. H. Cove $\dagger$ \\ B.Sc., M.B., Ch.B., M.R.C.P. \\ *Department of Medicine, University of Birmingham, Queen Elizabeth Hospital and \\ $\dagger$ Department of Diabetes and Endocrinology, Dudley Road Hospital, Birmingham
}

\begin{abstract}
Summary
Continuous 24-hr urine collections were made by 17 subjects during a trek to $\mathbf{5 4 0 0} \mathrm{m}$. Fluid intake was recorded by diary. Weight and fat folds were measured daily. The results were compared with daily measurements of packed cell volume (PCV) and reticulocyte count. Early fluid retention was matched by a fall in PCV. There was a diuresis with negative fluid balance towards the end of the ascent and again early in descent. There was a slight trend for fluid retention to occur in those most affected by acute mountain sickness but the effect was not marked.
\end{abstract}

\section{Introduction}

The experience of passing large volumes of urine on arrival at high altitude and during descent is well known to mountaineers (Ward, 1975). Singh et al. (1969) reported that Indian soldiers who passed copious urine when rapidly transferred to altitudes of $3350-5500 \mathrm{~m}$ did not develop acute mountain sickness (AMS) whereas those who were oliguric became ill. Other studies where subjects were transferred acutely to altitudes such as Pike's Peak in Colorado (Krzywicki et al., 1971; Consolazio et al., 1968; Janoski et al., 1969) or in the Swiss Alps (Slater et al., 1969) or exposed to simulated high altitude in hypobaric chambers (Hogan et al., 1973) have not resulted in a significant diuresis.

The present study was designed to monitor a trek to altitude in the Himalayas firstly to see if a diuresis occurred and secondly to relate fluid output to AMS which was anticipated in a number of the party. In addition, weight change, fat-fold thickness, packed cell volume and plasma albumin were documented since these measurements are indirectly related to changes in fluid balance. It was found that all members of the group with one exception had diuresis at altitude but that this was not related to AMS. Changes in the other measurements suggested that fluid may have been retained during the early part of the trek and loss of this retained fluid may have accounted for the diuresis at altitude.

\section{Methods}

Each member of the party passed all urine into 2-litre polythene bottles containing 1-2 ml of 1/1000 sodium merthiolate. Twenty-four-hr collection periods began at 5 p.m. each day. An estimate of fluid input was made by recording the volume of all fluids consumed in personal notebooks. No estimation of the water content of food was made nor was water of oxidation calculated. Weight was measured daily (Harvey et al., 1979). Blood was taken each morning before rising into heparinized syringes. Packed cell volume (PCV) was measured immediately using a microhaematocrit centrifuge. Equal volumes of blood and methylene blue were mixed and after incubation for $\mathbf{3 0}$ min a slide was made, air dried and stored for reticulocyte estimations on return to England. Two hundred cells were counted. After centrifugation of the remaining blood the supernatant plasma was mixed with sodium merthiolate at an approximate concentration of $1 / 1000$ and stored at ambient temperatures. Plasma albumin was estimated on an automatic analyser by the bromocresol green dye binding technique (Westgard and Poquette, 1972).

\section{Results}

The urine output and estimated fluid input are shown in Fig. 1. Fluid input was maximal during the first 5 days of the trek which was through tropical vegetation and temperatures. There was a significant rise in urine output with a peak at day 9 at an altitude of $3500 \mathrm{~m}$. At this time the party's fluid input and output were approximately equal but if insensible losses are taken into account, the group as a whole was in negative balance. The maximum urine output of any member was $3400 \mathrm{ml}$; most members noticed the increase in urine output and with one exception all members had at least one day between days 7-11 where the urine output exceeded the fluid input. This period of negative fluid balance was not associated with a feeling of thirst. Above $4400 \mathrm{~m}$ urine output declined but another diuresis was noted during descent. 


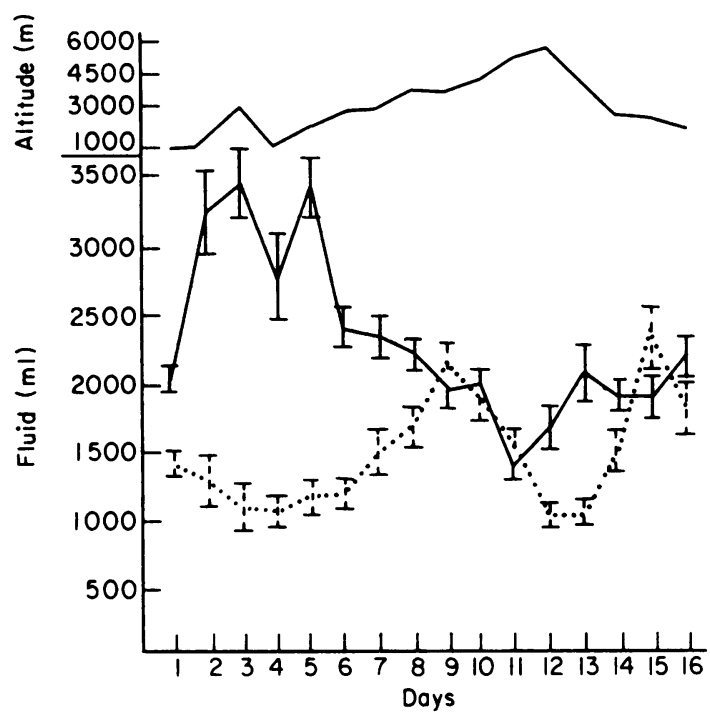

FIG. 1. Estimated fluid input and urine output related to altitude (Mean 17 members \pm s.e.mean). —— Fluid input ;..... urine output.

The mean weight (Fig. 2) declined very little over the first 9 days but there was a sudden drop in weight by a mean of $1.88 \mathrm{~kg}$ between day 9 and day 11 which coincided with the period of maximum diuresis. Over the first 12 days of the trek the mean body weight declined by $185 \mathrm{~g} /$ day $(P<0.001)$ and the mean body fat estimated from caliper measurements declined by an average of $173 \mathrm{~g} /$ day $(P<0.001)$.

The PCV and plasma albumin fell during the early part of the trek and returned to base line values at altitude (Fig. 2). The reticulocyte count never rose above $2 \%$ suggesting that the rise in PCV was related to a fluid shift. The maximum rise in PCV and albumin occurred at the time of maximum diuresis and weight loss.

Five subjects suffered marked AMS (Fletcher, $1979)$ and 5 were free of virtually all symptoms. When these 2 groups were compared there were no significant differences in the weight or PCV between affected and unaffected individuals (Fig. 3). There was a tendency for the unaffected group to be in greater negative fluid balance than the affected group but this did not reach statistical significance.

\section{Discussion}

The fall of PCV and plasma albumin during the first 7 days of the trek was totally unexpected. The decline was not associated with a rise in plasma bilirubin or with haemoglobinuria and was presumably related either to a fluid shift from the extra to the intravascular space or an overall retention of
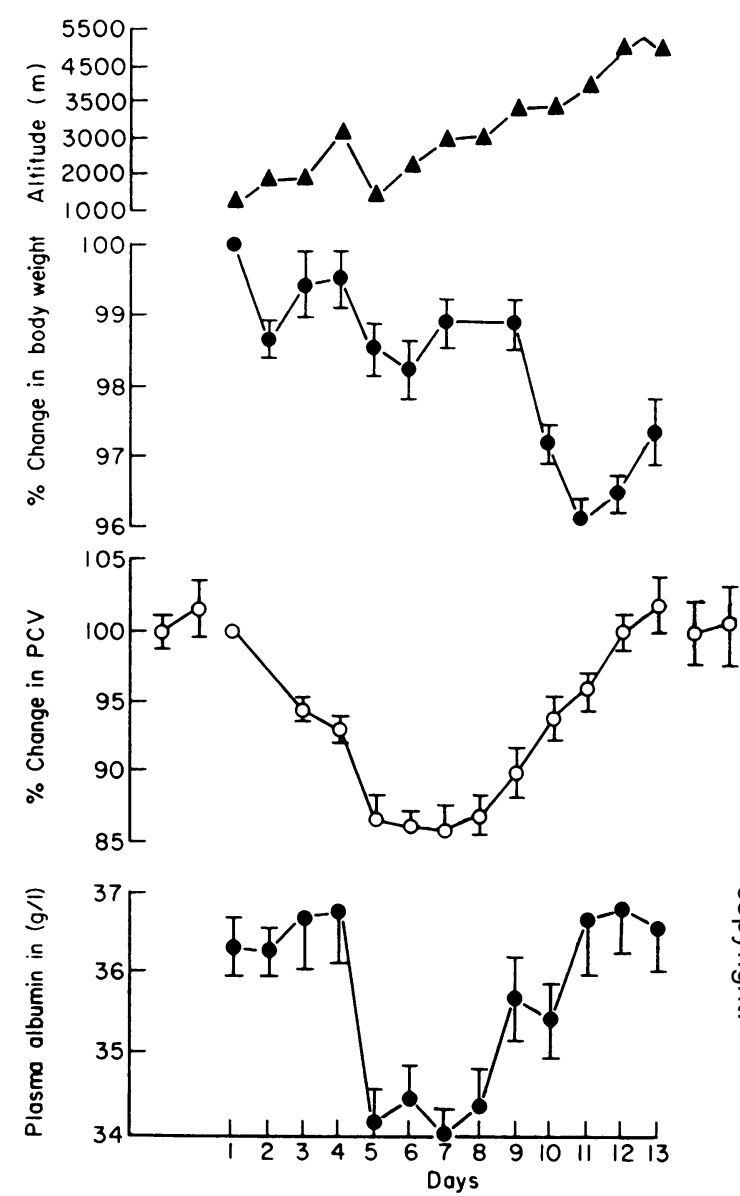

FIG. 2. Change in weight, PCV and plasma albumin related to altitude (Mean 17 members \pm s.e.mean). First 2 and last 2 points on PCV represent values for the group before leaving and after returning to Birmingham.

fluid. Total body weight declined very little during this period whereas fat fold thickness measurements indicated a gradual loss of body fat. In addition 2 members of the party noted oedema of the hands and ankles on day 7 and thus it is possible that there was an overal! retention of fluid causing the fall in albumin and PCV and masking the gradual decline of total body fat. At day 9 at an altitude of $3500 \mathrm{~m}$ there was a significant diuresis associated with a rapid loss of weight and a rise in PCV and plasma albumin to baseline values. The rise in PCV was not associated with a reticulocytosis.

A rise in PCV associated with a fall in plasma volume at altitude has been noted in many studies (Krzywicki et al., 1969; Hannon, Chinn and Shields, 1969; Jung et al., 1971). The mechanism is related to loss of extracellular fluid into the cells or into 

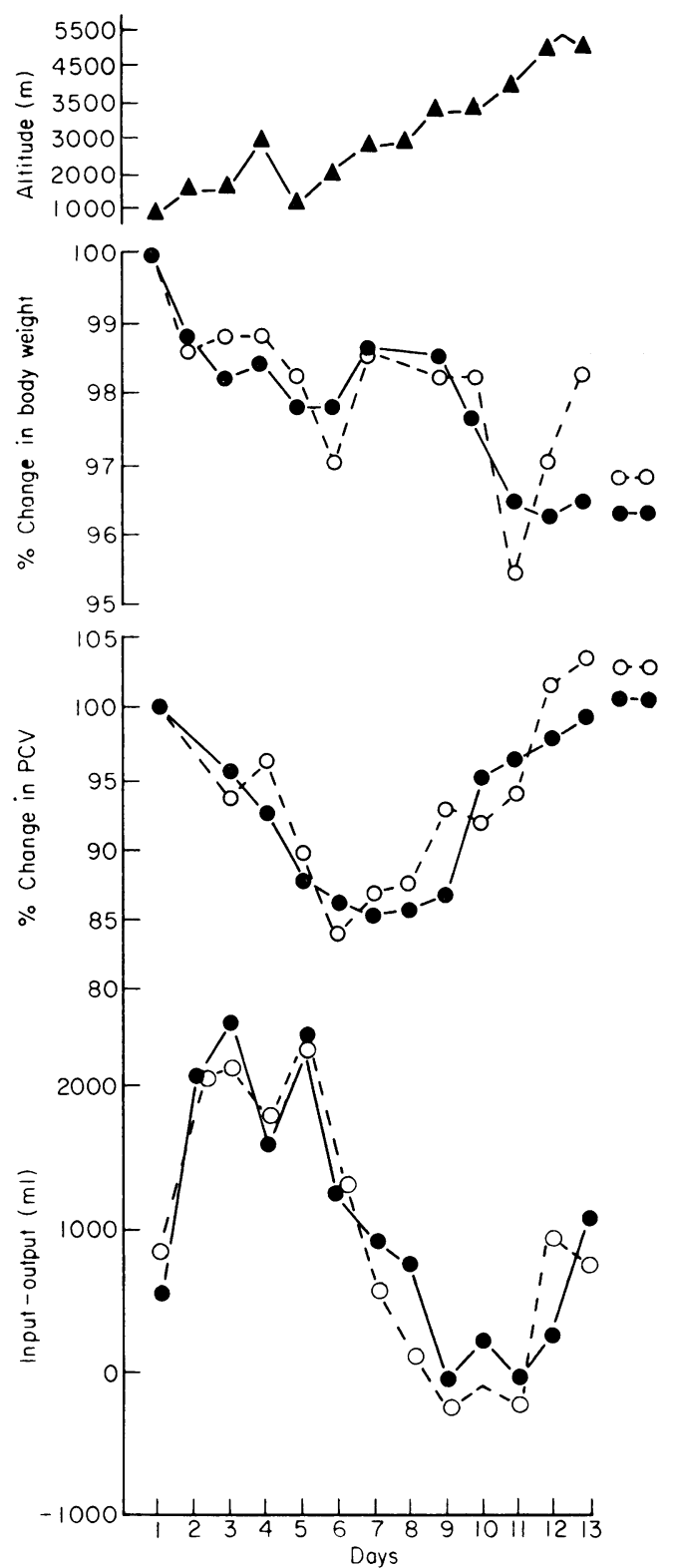

Fig. 3. Body weight, PCV and fluid input-fluid output in 5 members most affected by AMS (-O) and in 5

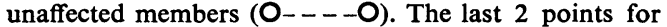
weight and PCV are values after return to Birmingham.

the urine since a rise in PCV due to increased red cell production occurs only after several days' or weeks' stay at altitude (Hannon et al., 1969). The studies recording a rise in PCV have been from normal to increased values. The change from subnormal to normal values as noted in this study have not been recorded at altitude although a similar fall and rise of PCV have been noted in a low altitude trekking party (E. S. Williams, personal communication). It is possible that the fall in PCV early in a trek protects in some way from severe altitude sickness since it is known that subjects acutely transferred to altitude have more severe symptoms (Hackett, Rennie and Levine, 1969).

The maximum diuresis occurred at $3500 \mathrm{~m}$ and represented approximately twice the fluid output found early in the trek. Currie and Ullman (1961) have shown that a diuresis can be induced by overbreathing and the production of increased negative intra-thoracic pressure. In this study however the maximum urine output did not occur at either maximum height or at periods of maximum effort. The diuresis may be related to the fluid retention early in the trek since in many studies in subjects transferred acutely to altitude there has been little evidence of a significant diuresis (Krzywicki et al., 1971; Consolazio et al., 1968; Janoski et al., 1969; Slater et al., 1969; Hogan et al., 1973).

If, as Singh et al. (1969) suggest, high altitude pulmonary and cerebral oedema are related to fluid retention, the authors would have expected the PCV to be lower, weight higher and a positive fluid balance in those most effected, especially in the days immediately before the first symptoms occurred (day 11) but this was not the case. They conclude that, although profound fluid shifts occur during a trek to altitude, the development of AMS is largely unrelated to these changes.

\section{References}

Consolazio, F.C., Matoush, le R.O., Johnson, H.L. \& DAws, T.A. (1968) Protein and water balances of young adults during prolonged exposure to high altitude (4300 meters). American Journal of Clinical Nutrition, 21, 154.

Currie, J.C.M. \& Ullman, E. (1961) Polyuria during experimental modifications of breathing. Journal of Physiology, 155, 438.

FlETCHER, R.F. (1979) BMRES 1977 expedition: Signs and symptoms. Postgraduate Medical Journal, 55, 461.

Hackett, P.H., Rennie, D. \& Levine, H.D. (1976) The incidence, importance and prophylaxis of acute mountain sickness. Lancet, ii, 1149.

Hannon, J.P., Chinn, K.S.K. \& Shields, J.L. (1969) Effects of acute high-altitude exposure on body fluids. Federation Proceedings, 28, 1178.

Hogan III, P.R., Kotchen, T.A., Boyd III, A.E. \& Hartley, L.H. (1973) Effect of altitude on renin-aldosterone system and metabolism of water and electrolytes. Journal of Applied Physiology, 35, 385.

Janoski, A.H., Whitten, B.K., Shields, J.L. \& Hannon, J.P. (1969) Electrolyte patterns and regulation in man during acute exposure to high altitude. Federation Proceedings, 28, 1185.

Jung, R.C., Dill, C.B., Horton, R. \& Hovath, S.M. (1971) Effects of age on plasma aldosterone level and hemoconcentration at altitude. Journal of Applied Physiology. 4, 593. 
Krzywicki, H.J., Consolazio, C.F., Johnson, H.L., Nielson Jr., W.C. \& BarnharT, R.A. (1971) Water metabolism in humans during acute high-altitude exposure (4,300 m). Journal of Applied Physiology, 30, 806.

Krzywicki, H.J., Consolazio, C.F., Matoush, le R.O., Johnson, H.L. \& BARNhaRT, R.A. (1969) Body composition changes during exposure to altitude. Federation Proceedings, 28, 1190.

Singh, I., Khanna, P.K., Srivastava, M.C., Lal, M., Roy, S.B. \& SubramanYan, C.S.V. (1969) Acute mountain sickness. New England Journal of Medicine, 280, 175.
Slater, J.D.H., Williams, E.S., EdWards, R.H.T., Ekins, R.P., Sonksen, P.H., Beresford, C.H. \& MCLaughlin, MARJORIE (1969) Potassium retention during the respiratory alkalosis of mild hypoxia in man: its relationship to aldosterone secretion and other metabolic changes. Clinical Science, 37, 311.

WARD, M. (1975) Mountain Medicine, p. 66. Gosby Lockwood Staples, London.

Westgard, J.O. \& Poquette, M.A. (1972) Determination of the serum albumin with the SMA 1260 by a bromocresol green dye-binding method. Clinical Chemistry, 18, 647.

\section{Discussion}

MR M. P. WARD: Did you notice any peripheral or facial oedema at the same time as the plasma volume went up, about the seventh day?

DR A. Howell: Yes, one person had marked peripheral oedema at that time.

MR WARD: How much exercise were you doing each day?

DR Howell: It varied. Between the fourth and ninth day we were walking 10 to $20 \mathrm{~km}$ and going up in all 1000-1500 m each day.

Professor E. S. Williams: I was interested to note the discrepant results concerning aldosterone. There is still uncertainty about the depression of aldosterone with hypoxia.
DR C. S. Houston: Unreported aldosterone measurements of ours coincide with these but our reported ones do not. We abandoned hormone studies because without daily sodium and potassium balances they are impossible to interpret.

Professor Williams: In our relatively definitive work we controlled the diet very strictly.

DR J. G. DICKINSON: What about diarrhoea?

DR Howell: We had some diarrhoea in the first 7 days, which might account for the rise in aldosterone then but there was little diarrhoea later in the trek. 